\title{
Abdominal wall recurrence of a gastrointestinal stromal tumor: case report
}

\author{
Hajar Hachim, Anass Mohammed Majbar ${ }^{*}$ (D, Mouna Alaoui, Mohamed Raiss, Farid Sabbah, Abdelmalek Hrora \\ and Mohamed Ahallat
}

\begin{abstract}
Introduction: The gastrointestinal stromal tumors (GIST) are mesenchymal tumors, most commonly affecting the stomach and small bowel. Only few cases of port-site recurrence after laparoscopic treatment have been reported. We herein report the case of a parietal recurrence on the extraction incision site, 7 years after laparoscopic surgery for small bowel GIST.

Case report: A 47 years-old female patient was hospitalized in November 2007 for isolated pelvic pain. CT scan showed an intestinal tumor with a benign aspect measuring $50 \mathrm{~mm}$. A laparoscopy-assisted resection was performed. Surgical exploration found a $7 \mathrm{~cm}$ small bowel tumor. It was extracted through a supra-pubic transversal incision without a wound protector and then resected. Histologic analysis revealed an intestinal GIST with high aggressive potential (five mitosis per field), with CD117 positive at the immunohistochemical examination. The patient had no adjuvant chemotherapy. Seven years later, the patient was readmitted for an abdominal mass at the site of the supra-pubic scar. Abdomino-pelvic CT scan showed a $10 \times 7.5 \mathrm{~cm}$ solid mass of the abdominal wall. Percutaneous biopsies were done and the pathological analysis revealed a mesenchymal-cell tumor, positive to CD117 and DOG1 at the immunohistochemical examination. Final diagnosis was abdominal wall recurrence of GIST secondary to tumorcontamination during the first surgery.
\end{abstract}

Conclusion: Abdominal wall recurrence of GIST after laparoscopic surgery is rarely reported. This complication should be avoided with preventive measures such as the use of extraction bags or wound protectors.

Keywords: Gastrointestinal stromal tumor, Laparoscopic surgery, Neoplasm recurrence

\section{Introduction}

Gastrointestinal stromal tumors are rare tumors secondary to a malignant proliferation of mesenchymal cells. They affect more frequently the stomach and the small bowel in comparison with other segments of the digestive tract (Landi et al. 2015).

Enbloc surgical resection (R0) with a safety margin of $1-2 \mathrm{~cm}$ is actually the only potentially curative treatment. Imatinib based adjuvant chemotherapy is complementary to the surgery to improve the survival and the disease free survival. Laparoscopy has been used successfully in the treatment of digestive GIST with minor

*Correspondence: anassmajbar@gmail.com

Clinique Chirurgicale C, Ibn Sina University Hospital, 10090 Rabat,

Morocco complications. Particularly, very few cases of port sites recurrences have been reported (Furukawa et al. 2012).

We herein report the case of an abdominal wall recurrence on the site of the extraction incision of a laparoscopically resected small bowel stromal tumor.

\section{Case report}

We report the case of a 47 years-old female patient, who was referred to our unit in November 2007 for isolated pelvic pain. Clinical examination was without abnormalities. The abdominal pelvic ultrasound revealed a $60 \mathrm{~mm}$ hypoechoic and heterogeneous mass in the right iliac fossa. The abdominal pelvic computed tomography showed a tumor measuring $50 \times 50 \times 48 \mathrm{~mm}$, attached to the anterior wall of the cecum and the right colon (Fig. 1).

\section{Springer}

(c) 2015 Hachim et al. This article is distributed under the terms of the Creative Commons Attribution 4.0 International License (http://creativecommons.org/licenses/by/4.0/), which permits unrestricted use, distribution, and reproduction in any medium, provided you give appropriate credit to the original author(s) and the source, provide a link to the Creative Commons license, and indicate if changes were made. 


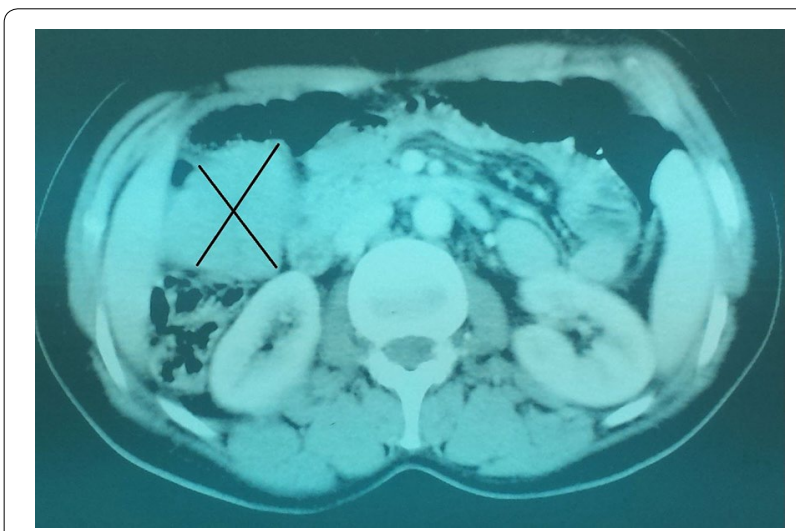

Fig. 1 Computed tomography showing the intestinal tumor

The multidisciplinary meeting decided to perform a diagnostic and therapeutic laparoscopy. The laparoscopic exploration showed a $70 \mathrm{~mm}$ tumor of the small bowel, $70 \mathrm{~cm}$ upstream the last ileal loop. The tumor was extracted through a small suprapubic incision, without the use of a wound protector. It was resected with a safety margin of $2 \mathrm{~cm}$ and an end-to-end anastomosis was performed. The postoperative course was marked by an infection of the extraction's site. The pathology specimen findings revealed a stromal tumor with a high aggressive potential (five mitosis per field), positive to CD117 at the immunohistochemical examination. An Imatinib adjuvant therapy was indicated, but the patient did not receive it because of financial considerations.

The patient had a postoperative follow-up (clinical examination, abdominal ultrasonography and abdominal computed tomography alternately) every 3 months during the first year, then every 6 months during the second and the third year. After that, the patient stopped her follow-up on her own.

Seven years after the surgical resection, the patient was hospitalized for a pelvic mass underneath the old scar. The abdominal examination found a mass measuring $60 / 70 \mathrm{~mm}$. The abdominal pelvic CT scan showed a $100 / 75 \mathrm{~mm}$ solid mass of the abdominal wall alongside to the pubic symphysis (Fig. 2).

Percutaneous biopsies of the tumor were made and histologic examination showed an aspect of low-grade malignancy GIST. An enbloc surgical resection of the tumor was performed, with a safety margin of $1 \mathrm{~cm}$. The wall defect measured $6 \mathrm{~cm}$ in diameter and it was closed by direct suture. The pathological examination revealed a tumoral proliferation of spindle atypical cells with mitotic signs. The immunehistochemical examination showed an important positivity to CD117 and DOG1. The patient received adjuvant chemotherapy (Imatinib).

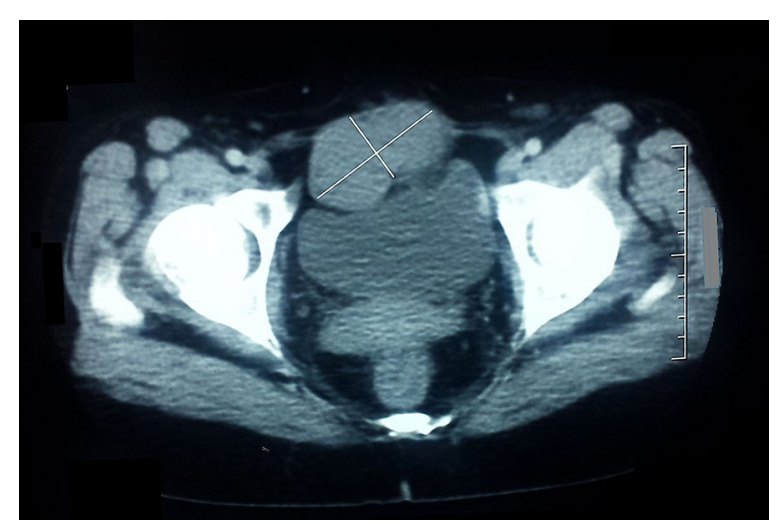

Fig. 2 Computed tomography showing the abdominal wall recurrence

\section{Discussion}

We herein report the case of parietal recurrence on the extraction site of a GIST, after a laparoscopy-assisted resection. This is a rare event and only few cases have been reported in the literature, mainly port-site metastasis (Kaczmarek et al. 2001; Davies et al. 2008; Furukawa et al. 2012) (Table 1).

Several mechanisms may be responsible of GIST parietal recurrences (on the port sites of the extraction incisions) (Martinez et al. 1995; Schaeff et al. 1998) including: the high pressure of $\mathrm{CO}_{2}$ insufflation; the excessive manipulation of the tumor during surgery (stromal tumors are easily friable because of their necrotic character) (Landi et al. 2015), and secondary dissemination because of lack of protection of the abdominal wall during specimen extraction.

This complication is preventable with simple measures such as: the extraction of the specimen in a wound protector, careful manipulation of the tumor to avoid breaking; peritoneal washing with cytocidal or anti-adhesive solution (Kaczmarek et al. 2001; Shoup et al. 2002; Davies et al. 2008; Furukawa et al. 2012) and even the resection of the port sites. The use of the wound protector aims to protect the wound edges from contamination (infectious or tumoral). A meta-analysis of randomized controlled trials evaluating the use of wound protectors in gastrointestinal and biliary surgical procedures and the impact on surgical site infections (SSIs) showed nearly $50 \%$ decrease in SSIs (RR $=0.55$; $95 \%$ CI, 0.31$0.98 ; \mathrm{p}=0.04$ ) just by using a wound protector (Edwards et al. 2012). In our case, not using a wound protector was responsible of a SSI immediately after the surgery and a tumor contamination responsible of a parietal recurrence 7 years later.

The influence of the surgeon was also suggested responsible of 0-21\% of port-site recurrences after a laparoscopy 
Table 1 Summary of previously reported cases of GIST parietal recurrence in the literature (Kaczmarek et al. 2001; Davies et al. 2008; Furukawa et al. 2012)

\begin{tabular}{|c|c|c|c|c|c|c|}
\hline & Localization & Tumor size & Intervention & Recurrence site & $\begin{array}{l}\text { Specimen results/ } \\
\text { mitotic index }\end{array}$ & $\begin{array}{l}\text { Extraction preventive } \\
\text { measures }\end{array}$ \\
\hline $\begin{array}{l}\text { Kaczmarek } \\
\text { et al. (2001) }\end{array}$ & Stomach GIST & $4 \times 4 \mathrm{~cm}$ & $\begin{array}{l}\text { Endoscopic wedge } \\
\text { resection }\end{array}$ & Port-site metastasis & $>5$ & No information \\
\hline $\begin{array}{l}\text { Davies et al. } \\
\text { (2008) }\end{array}$ & Stomach GIST & $13 \mathrm{~cm}$ & $\begin{array}{l}\text { Laparoscopic diagnos- } \\
\text { tic }+ \text { biopsies }\end{array}$ & Port-site metastasis & $\begin{array}{l}\text { Malignant GIST+ } \\
\text { Strongly positive CD117 }\end{array}$ & No information \\
\hline $\begin{array}{l}\text { Furukawa } \\
\text { et al. (2012) }\end{array}$ & Stomach GIST & - & $\begin{array}{l}\text { Laparoscopic partial } \\
\text { gastrectomy }\end{array}$ & $\begin{array}{l}\text { Umbilical wound } \\
\text { recurrence }\end{array}$ & $\begin{array}{l}\text { GIST } \\
\text { c-Kit+ }\end{array}$ & No information \\
\hline
\end{tabular}

performed for cancer. An experimental study on a porcine model showed a tumor recurrence in $63.8 \%$ in the control group versus $13.8 \%$ in the protective measures group (Schneider et al. 2001) suggesting that the use of standardized protective measures might reduce greatly the incidence of port-site recurrence (Franklin et al. 1996). The protective measure in this study were: prevention of gas leaks, fixation of trocars, protection of the extraction port, rinsing of instruments with cytotoxic substances such as povidone iodine or hydrogen peroxyde, and closure of peritoneal wounds (Wang et al. 1999).

Table 2 Estimation of the recurrence risk or death linked to the disease in localized and resecable GISTs depending on tumor size and the mitotic index (Fletcher et al. 2002)

\begin{tabular}{lll}
\hline Risk & Maximum diameter & Mitotic index $^{\text {a }}$ \\
\hline Very low risk & $<2 \mathrm{~cm}$ & $<5$ \\
Low risk & $2-5 \mathrm{~cm}$ & $<5$ \\
Intermediate risk & $<5 \mathrm{~cm}$ & $6-10$ \\
& $5-10 \mathrm{~cm}$ & $<5$ \\
High risk & $>5 \mathrm{~cm}$ & $>5$ \\
& $>10 \mathrm{~cm}$ & "Whatever" \\
& "Whatever" & $>10$
\end{tabular}

a Per 50 fields
Although our patient had a primary resectable localized GIST, a complete resection with negative microscopic margins do not prevent recurrences. The estimation of recurrence and death risks related to the GIST is based on the tumor size, mitotic rate and the site of the tumor. This estimation allows the selection of patients for adjuvant Imatinib and identifying their prognosis (Fletcher et al. 2002; Miettinen and Lasota 2006; Dematteo et al. 2008) (Tables 2, 3). Our patient had initially a $70 \mathrm{~mm}$ tumor, located in the small bowel, with five mitosis per field, positive to CD117 and no protection measures during the extraction procedure. So it would be reasonable to label her into a "high risk" category, even though she had an intermediate risk of recurrence (24\%) according to the stratification models (Fletcher et al. 2002; Miettinen and Lasota 2006). A study comparing 3 vs 1 year of Imatinib (400 mg/day) in the high-risk GIST patients showed that the recurrence-free survival was $86.6 \%$ in 3-years arm versus $60.1 \%$ in the 1 -year arm. Five-years overall survival was also significantly better in the 3-years Imatinib arm versus the 1-year arm (92 vs. $81.7 \%, p=0.019$ ) (George et al. 2009). Our patient did not receive Imatinib after the first surgery. Adjuvant chemotherapy would have reduced the risk of recurrence (Wang et al. 1999).

Table 3 Estimation of the recurrence risk or death linked to the disease in localized and resecable GISTs depending on tumor size, the tumor localization and the mitotic index (Miettinen and Lasota 2006)

\begin{tabular}{|c|c|c|c|c|c|}
\hline Tumor's maximum diameter $(\mathrm{cm})$ & Mitotic index ${ }^{b}$ & Stomach GIST (\%) & Small bowel GIST (\%) & Duodenal GIST (\%) & Rectal GIST (\%) \\
\hline$\leq 2$ & $\leq 5$ & 0 & 0 & 0 & 0 \\
\hline$>2 \leq 5$ & $\leq 5$ & 1.9 & 4.3 & 8.3 & 8.5 \\
\hline$>5 \leq 10$ & $\leq 5$ & 3.6 & 24 & $-{ }^{\mathrm{a}}$ & $-^{a}$ \\
\hline$>10$ & $\leq 5$ & 12 & 52 & 34 & 57 \\
\hline$\leq 2$ & $>5$ & 0 & 50 & $-^{\mathrm{a}}$ & 54 \\
\hline$>2 \leq 5$ & $>5$ & 16 & 73 & 50 & 52 \\
\hline$>5 \leq 10$ & $>5$ & 55 & 85 & $--^{\mathrm{a}}$ & $--^{a}$ \\
\hline$>10$ & $>5$ & 86 & 90 & 86 & 71 \\
\hline
\end{tabular}

a Insufficient number of patients to estimate

b Per 50 Fields 


\section{Conclusion}

Parietal recurrence of GIST after laparoscopy is rarely reported. They are considered as metastasis. This complication could be avoided with preventive measures such as the use of extraction bags or wound protectors.

\section{Consent}

The patient gave signed statement, which authorises the use of her personal and/or medical information in the publication of this study.

\section{Abbreviations}

GIST: gastrointestinal stromal tumor; CT: computed tomography; SSI: surgical site infection.

\section{Authors' contributions}

$\mathrm{HH}$ and MMA equally contributed in drafting the manuscript. AM, MR, FS, AH and $M A$ revised critically the article. All authors read and approved the final manuscript.

\section{Acknowledgements \\ None.}

\section{Compliance with ethical guidelines}

\section{Competing interests}

The authors declare that they have no competing interests.

Received: 23 March 2015 Accepted: 6 August 2015

Published online: 19 August 2015

\section{References}

Davies AR, Ahmed W, Purkiss SF (2008) Port site metastasis following diagnostic laparoscopy for a malignant gastro-intestinal stromal tumour. World J Surg Oncol 6:55. doi:10.1186/1477-7819-6-55
Dematteo RP, Gold JS, Saran L et al (2008) Tumor mitotic rate, size, and location independently predict recurrence after resection of primary gastrointestinal stromal tumor (GIST). Cancer 112:608-615. doi:10.1002/cncr.23199

Edwards JP, Ho AL, Tee MC et al (2012) Wound protectors reduce surgical site infection: a meta-analysis of randomized controlled trials. Ann Surg 256:53-59. doi:10.1097/SLA.0b013e3182570372

Fletcher CD, Berman JJ, Corless C et al (2002) Diagnosis of gastrointestinal stromal tumors: a consensus approach. Hum Pathol 33:459-465

Franklin ME, Rosenthal D, Abrego-Medina D et al (1996) Prospective comparison of open vs. laparoscopic colon surgery for carcinoma. Five-year results. Dis Colon Rectum 39:S35-S46

Furukawa M, Izumi S, Asano H et al (2012) Late umbilical port-site recurrence of a gastrointestinal stromal tumor with an acquired PDGFR $\alpha$ mutation after laparoscopic resection: report of a case. Surg Laparosc Endosc Percutan Tech 22:e109-e111. doi:10.1097/SLE.0b013e3182479e1f

George S, Blay JY, Casali PG et al (2009) Clinical evaluation of continuous daily dosing of sunitinib malate in patients with advanced gastrointestinal stromal tumour after imatinib failure. Eur J Cancer 45:1959-1968. doi:10.1016/j.ejca.2009.02.011

Kaczmarek D, Blanc P, Balique JG, Porcheron J (2001) Port-site metastasis after laparoscopic resection of a duodenal stromal tumor. Ann Chir 126:677-679

Landi B, Blay JY, Bonvalot S et al (2015) Tumeurs stromales gastro-intestinales (GIST). Thésaurus National de Cancérologie Digestive (TNCD). http:// www.snfge.org/content/12-tumeurs-stromales-gastro-intestinales-gist

Martinez J, Targarona EM, Balagué C et al (1995) Port site metastasis. An unresolved problem in laparoscopic surgery. A review. Int Surg 80:315-321

Miettinen M, Lasota J (2006) Gastrointestinal stromal tumors: pathology and prognosis at different sites. Semin Diagn Pathol 23:70-83

Schaeff B, Paolucci V, Thomopoulos J (1998) Port site recurrences after laparoscopic surgery. A review. Dig Surg 15:124-134

Schneider C, Jung A, Reymond MA et al (2001) Efficacy of surgical measures in preventing port-site recurrences in a porcine model. Surg EndosC 15:121-125

Shoup M, Brennan MF, Karpeh MS et al (2002) Port site metastasis after diagnostic laparoscopy for upper gastrointestinal tract malignancies: an uncommon entity. Ann Surg Oncol 9:632-636

Wang PH, Yuan CC, Lin G et al (1999) Risk factors contributing to early occurrence of port site metastases of laparoscopic surgery for malignancy. Gynecol Oncol 72:38-44. doi:10.1006/gyno.1998.5128

\section{Submit your manuscript to a SpringerOpen ${ }^{\circ}$ journal and benefit from:}

- Convenient online submission

- Rigorous peer review

- Immediate publication on acceptance

- Open access: articles freely available online

- High visibility within the field

- Retaining the copyright to your article

Submit your next manuscript at $>$ springeropen.com 